\title{
Índice de desenvolvimento sustentável para municípios: um estudo sobre o nível de sustentabilidade de Passo Fundo-RS
}

\author{
Eluane Parizotto Seidler ${ }^{1}$ \\ Tanice Andreatta ${ }^{2}$ \\ Rafael Lopes Ferreira ${ }^{3}$
}

\begin{abstract}
RESUMO
O objetivo deste artigo é identificar o nível de sustentabilidade do município de Passo Fundo-RS, em relação aos demais municípios do Corede Produção. Trata-se de uma pesquisa aplicada, baseada na utilização do Índice de Desenvolvimento Sustentável para Municípios (IDSM), metodologia proposta por Martins e Cândido (2008) para mensurar o nível de sustentabilidade adaptada para os municípios. Os dados dos indicadores referentes aos municípios foram obtidos nas principais bases de dados e portais institucionais, pesquisados no ano de 2017. Os resultados obtidos apontam que o município de Passo Fundo apresenta nível aceitável de sustentabilidade, conforme os parâmetros utilizados no método. Este índice é obtido, sobretudo, pelo desempenho ideal/aceitável das dimensões cultural e político-institucional, no entanto, alguns indicadores apresentaram índice crítico como uso da terra, ou em alerta, os indicadores de dinâmica populacional e emprego e renda, que são fundamentais para o desenvolvimento sustentável. Para estudos futuros sugere-se aplicar o Índice de Desenvolvimento Local Sustentável, que incorpora a participação de atores sociais na priorização de questões do desenvolvimento local. Ainda, a pesquisa gerou um banco de dados que proporciona identificar o IDSM para todos os municípios do Corede Produção, bem como o estudo do nível de sustentabilidade da Região da Produção.

Palavras-chave: desenvolvimento local, idsm, indicadores, sustentabilidade.
\end{abstract}

\section{Sustainable development index for municipalities: a study on the level of sustainability of Passo Fundo, RS State, Brazil}

\begin{abstract}
The objective of this article is to identify the level of sustainability of the municipality of Passo Fundo-RS, in relation to the other municipalities of Corede Produção. This is an applied research, based on the use of the Sustainable Development Index for Municipalities (IDSM), a methodology proposed by Martins and Cândido (2008) to measure the level of sustainability adapted for the municipalities. The data of the indicators referring to the municipalities were obtained in the main databases and institutional portals, researched in 2017. The results obtained indicate that the municipality of Passo Fundo presents an acceptable level of sustainability, according to the parameters used in the method. This index is obtained, above all, by the ideal/acceptable performance of the cultural and political-institutional dimensions, however, some indicators presented critical index as land use, or on alert, the indicators of population dynamics and employment and income, which are fundamental for sustainable development. For future studies it is suggested to apply the Sustainable Local Development Index, which incorporates the participation of social actors in the prioritization of local development issues. Furthermore, the research generated a database that provides identification of IDSM for all municipalities of Corede Produção, as well as the study of the level of sustainability of the Production Region.
\end{abstract}

Key-words: local development, idsm, indicators, sustainability.

\footnotetext{
1 Mestra em Agronegócios pela Universidade Federal de Santa Maria (UFSM). Professora Substituta do Departamento de Administração da UFSM, Campus Palmeira das Missões-RS, Brasil. E-mail: eluanepseidler@gmail.com

${ }^{2}$ Doutora em Desenvolvimento Rural pela Universidade Federal do Rio Grande do Sul (UFRGS). Professora do Departamento de Ciências Econômicas e do Programa de Pós-Graduação em Agronegócios da Universidade Federal de Santa Maria (UFSM) - Campus Palmeira das Missões, RS, Brasil.

${ }^{3}$ Mestre em Ciência e Tecnologia Ambiental pela Universidade Tecnológica Federal do Paraná (UTFPR). Professor orientador de trabalho de conclusão de curso (TCC) do Centro Universitário Internacional Uninter, Curitiba, PR, Brasil.
} 


\section{INTRODUÇÃO}

Ainda que se observe um conjunto de conceitos de desenvolvimento sustentável e/ou sustentabilidade, na prática, a operacionalização destes conceitos é bastante complexa. Atualmente, os esforços de diagnóstico, operacionalização e análise passam pela elaboração e aplicabilidade de métodos de avaliação de desenvolvimento sustentável.

É possível mensurar o desenvolvimento sustentável a partir de indicadores em diversas dimensões, com seus respectivos indicadores específicos. Um exemplo é o do Índice de Desenvolvimento Sustentável (IDS), proposto pelo Instituto Brasileiro de Geografia e Estatística (IBGE), com indicadores nacionais e estaduais. A construção de indicadores de desenvolvimento sustentável, no Brasil, é parte do conjunto de esforços internacionais para concretização dos princípios formulados na Conferência das Nações Unidas sobre Meio Ambiente e Desenvolvimento realizada no Rio de Janeiro, a Rio 92.

Os indicadores possibilitam o acompanhamento da sustentabilidade do desenvolvimento brasileiro nas dimensões ambiental, social, econômica e institucional, gerando uma gama abrangente de informações necessárias para conhecimento da realidade do País, como também para o planejamento e formulação de políticas públicas para o desenvolvimento sustentável (IBGE, 2015).

Um método específico para analisar o nível de desenvolvimento sustentável de municípios, denominado Índice de Desenvolvimento Sustentável para Municípios (IDSM), foi proposto por Martins e Cândido (2008). De um modo geral, essa metodologia é inovadora e com possibilidades reais de apoio ao processo de formulação e implementação de políticas públicas e privadas para a geração do desenvolvimento local sustentável, respeitando as particularidades de cada região.

Diante deste contexto, de análise e necessidade de mensurar o desenvolviemnto sustentável de um local ou de uma região, questiona-se qual o nível de sustentabilidade do município de Passo Fundo-RS, em relação aos demais municípios do Corede Produção?

De modo a responder ao problema de pesquisa, este artigo teve como objetivo identificar o nível de sustentabilidade do município de Passo Fundo-RS, em relação aos demais municípios do Corede Produção. A partir da aplicação do Índice de Desenvolvimento Sustentável para Municípios (IDSM), metodologia proposta por Martins e Cândido (2008). A escolha por este método se dá pelo fato dele ser proposto, especificamente, para mensurar o nível de sustentabilidade adaptada para os municípios. Tendo em vista o objetivo de se realizar esta análise no município de Passo Fundo.

Os Coredes (Conselhos Regionais de Desenvolvimento) foram criados em 1994, com o intuito de permitir a participação da sociedade civil no debate do desenvolvimento regional e nos destinos dos territórios gaúchos. Ao todo são 28 Coredes que estão divididos em nove regiões funcionais do Estado do Rio Grande do Sul (RS). O Corede Produção, está localizado na Região Funcional 9 (FINAMORE, 2010), é composto por 21 municípios, dentre eles, Passo Fundo.

A razão de escolha, para o estudo, do município de Passo Fundo em relação aos demais municípios do Corede Produção, é pelo fato dele ser o maior município da região, polo econômico e centro de gestão do território onde 1.321 municípios estão sob sua influência (FINAMORE, 2010).

O presente estudo justifica-se ao passo de possibilitar aos tomadores de decisão e/ou agentes sociais das intituições públicas e privadas de Passo Fundo, uma visão conjunta dos 
problemas, fraquezas e qualidades observados através dos indicadores do IDSM. Além de, contribuir para redirecionar as suas políticas, frente ao processo de mudança e a necessidade de novas posturas que gerem resultados satisfatórios para a construção de uma sociedade mais justa, a partir do desenvolvimento de forma equilibrada, equitativa e sustentável.

O artigo está organizado em cinco capítulos, a começar por esta introdução. O capítulo dois, aborda a fundamentação teórica acerca dos marcos de discussão do desenvolvimento sustentável e possibilidades de mensuração. Em seguida, no capítulo três, é descrito os procedimentos metodológicos, sobretudo, a framework do IDSM. Ainda, é apresentada a caracterização do município em estudo. Posteriormente, no capítulo quatro, são apresentados os resultados, ou seja, a análise dos indicadores de sustentabilidade para as dimensões cultural, social, demográfica, político-institucional, ambiental e econômica. Por fim, são apresentadas as considerações finais, no capítulo cinco.

\section{MARCOS DE DISCUSSÃO DO DESENVOLVIMENTO SUSTENTÁVEL E POSSIBILIDADES DE MENRURAÇÃO}

As discussões sobre desenvolvimento e suas dimensões passaram a despertar a atenção da sociedade, sobretudo, ao que tange as questões ambientais, a partir da década de 1970. Tais reflexões, em larga medida, levaram ao surgimento das primeiras constatações, que apontam que alguns dos recursos naturais explorados estavam se tornando escassos e que a agressão à natureza poderia levar ao comprometimento do progresso econômico, do bem-estar e da sobrevivência da humanidade no planeta (SOUZA, 2011).

A Conferência de Estocolmo, em 1972, foi uma das primeiras e mais importantes conferências que contemplou as questões relacionadas ao desenvolvimento e meio ambiente. $\mathrm{O}$ desenvolvimento sustentável tem sua definição concebida no Relatório de Brundtland, publicado em 1987, através do documento "Nosso Futuro Comum", como aquele desenvolvimento capaz de satisfazer as necessidades das gerações presentes sem comprometer as gerações futuras de satisfazerem suas próprias necessidades (CMMAD, 1991).

Posteriormente, outros eventos e/ou documentos foram agregando novos aspectos e dimensões quanto à necessidade do que poderia se denominar de desenvolvimento sustentável. Entre eles, destacam-se a Agenda 21, que foi acordada e assinada por 179 países, na Rio 92; a Cúpula Mundial sobre Desenvolvimento Sustentável, realizada em Johanesburgo na África do Sul (Rio+10); a Rio+20, ocorrida em 2012, novamente no Rio de Janeiro; e a Cúpula de Desenvolvimento Sustentável, em 2015, em New York, onde foram definidos os novos Objetivos de Desenvolvimento Sustentável (ODS) e a Agenda 2030 para o Desenvolvimento Sustentável (MINISTÉRIO DO MEIO AMBIENTE, 2016).

Outro conceito de desenvolvimento sustentável mundialmente utilizado é o proposto por Ignacy Sachs. O autor elaborou uma noção denominada de Ecodesenvolvimento ou desenvolvimento sustentável, onde recomenda a utilização de oito critérios distintos de sustentabilidade parcial: social, cultural, ecológica, ambiental, territorial, econômico, política nacional e internacional (SACHS, 2009).

Feil e Schreiber (2017) fazem uma discussão e buscam contribuir para o axioma de conceitos, para termos bastante notáveis e oportunos em nível global como: sustentável, sustentabilidade e desenvolvimento sustentável. Os autores conceituam o termo sustentável como um alicerce, uma espécie de "guarda-chuva", ou seja, a ideia de sustentável é suportada pelo processo de sustentabilidade e desenvolvimento sustentável, considerando a preocupação futura de existência de recursos naturais para garantia de continuação da vida humana. 
A sustentabilidade, por sua vez, é um termo que expressa a preocupação com a qualidade e propriedade do sistema global humano ambiental, abrangendo os aspectos ambientais, sociais e econômicos em equilíbrio mútuo. Por fim, o desenvolvimento sustentável é conceituado como uma estratégia utilizada, em longo prazo, para melhorar a qualidade de vida (bem-estar) da sociedade, ou seja, objetiva o crescimento econômico sem agressão ambiental humana. Assim, a condução da sustentabilidade e do desenvolvimento sustentável faz atingir o sustentável (FEIL; SCHREIBER, 2017).

\subsection{Métodos de avaliação de desenvolvimento sustentável}

No que concerne a análise dos indicadores de sustentabilidade, é preciso considerar que se trata ainda de um problema complexo o de mensurar o estágio de desenvolvimento de sociedades ou territórios, especialmente quando o paradigma é o desenvolvimento sustentável. Entretanto, há esforços expressivos da comunidade técnico-científica que vem resultando numa série de modelos e sistemas (SOUZA, 2011). Pode-se citar alguns indicadores, nacionais, como o Índice de Desenvolvimento Sustentável - IDS Brasil - (IBGE) e Índice de Desenvolvimento Humano - IDH - (Programa das Nações Unidas para o Desenvolvimento - PNUD). E municipais, como Indicadores Sociais Municipais - ISM - (IBGE), Índice de Desenvolvimento Humano Municipal - IDHM - (IBGE/PNUD), Índice Firjan de Desenvolvimento Municipal IFDM - (Firjan), Atlas do Desenvolvimento Humano no Brasil (PNUD), Índice de Desenvolvimento Socioeconômico RS - IDESE - (Fundação de Economia e Estatística - FEE) e o Índice de Desenvolvimento Sustentável para Municípios - IDSM - (MARTINS; CÂNDIDO).

Esse esforço também é refletido no segmento agrícola, na busca de avaliar a sustentabilidade de seus sistemas produtivos. Seidler et al. (2018), identificaram através dos estudos mais citados, vários métodos e ferramentas (nacionais e internacionais) de avaliação de sustentabilidade voltados para o meio rural. As autoras ressaltam que a maioria das ferramentas e/ou métodos de avaliação de sustentabilidade, contemplam questões relacionadas aos aspectos econômicos, sociais e ambientais. Porém, apresentam algum tipo de limitação, que devem então serem adaptados de acordo objetivo a ser atingido, bem como às especificidades tanto locais como regionais.

Historicamente o ponto de partida da análise da evolução dos indicadores de sustentabilidade é o Produto Interno Bruto (PIB) indicador de crescimento econômico, no entanto, ele não se propõe a medir o bem-estar e a sustentabilidade, dois aspectos de importância fundamental na discussão do desenvolvimento. Em 1972, Nordhaus e Tobin lançam a Medida de Bem-Estar Econômico Sustentável (MEW-S), medida de consumo e não de produção. Daly e Cobb Junior, em 1989, propuseram o Índice de Bem-Estar Econômico Sustentável (ISEW), que se refere ao bem-estar sustentável por habitante. Em 1990, o então conhecido Índice de Desenvolvimento Humano (IDH) foi proposto por Haq e Sen, no intuito de medir a qualidade de vida (VEIGA, 2010).

Em 1995, surgiram indicadores focados no grau de pressão sobre os recursos naturais como a "Pegada Ecológica", desenvolvida por Wackernagel e Rees e a "Poupança Genuína" proposto pelo Banco Mundial, que mede a variação no total de ativos econômicos importantes para o desenvolvimento. Neste mesmo ano, surgiram o Índice de Sustentabilidade Ambiental (ESI) e o Índice de Desempenho Ambiental (EPI) desenvolvido pelos pesquisadores de Yale e Columbia. O Progresso Genuíno (GPI - Genuine Progress Indicator), proposto pela ONG Redefining Progress, em 2004, faz a avaliação do progresso de uma nação, desempenho 
econômico e qualidade de vida, no entanto, tem pouco a ver com a ideia de sustentabilidade (VEIGA, 2010).

$\mathrm{Na}$ avaliação da capacidade relativa de medir as dimensões econômicas, ambientais e sociais do desenvolvimento sustentável considerando os índices: Índice de Riqueza (CWI), Pegada Ecológica (EF), Índice de Desempenho Ambiental (EPI), Índice de Sustentabilidade Ambiental (ESI), Índice de Poupança Genuína (GSI), Bem-estar Global Index (GWI), Índice do Planeta Feliz (HPI), Índice de Desenvolvimento Humano (IDH) e Índice de Sociedade Sustentável (SSI); apenas o SSI e o GSI contém indicadores em todas as três dimensões do desenvolvimento sustentável. Enquanto que os demais trabalham, principalmente, com os fatores de desenvolvimento socioeconômico ou sócio-ambiental das nações, com dois dos indicadores que tratam apenas de economia, o CWI; e dimensões ambientais, o EF (STREZOV; EVANS; EVANS, 2017).

A razão de pesquisas de desenvolvimento dos indicadores sociais deve-se à necessidade de informações para o planejamento e a execução de políticas concernentes à melhoria da qualidade de vida; na busca de dados que possam esclarecer, da forma mais precisa possível, a dinâmica de processos e as estruturas, os objetivos, as opiniões e os valores de cada sociedade específica. Se antes, esses dados eram fundamentalmente de teor econômico como o PIB per capita, por exemplo, atualmente foi identificado a necessidade de serem incorporados dados sociais e estatísticos mais abrangentes, como os relativos à demografia, à saúde e à educação (MARTINS; OLIVEIRA, 2005).

Os municípios podem desempenhar papel central no progresso local em direção ao desenvolvimento sustentável. O desenvolvimento de uma ferramenta de avaliação de desempenho apoiada por indicadores, para monitorar os aspectos de saúde, segurança e meio ambiente (Health, Safety and Environment - HSE) do desenvolvimento sustentável foi desenvolvida para municípios de megacidades, pois grande parte dos serviços e atividades dos municípios estão relacionados aos aspectos HSE. O conjunto de indicadores HSE visa apoiar as autoridades municipais no monitoramento do desempenho desses indicadores, assim como, estabelecer estratégias locais de desenvolvimento sustentável (MAPAR et al., 2017).

Para Martins e Cândido (2008), os sistemas de indicadores de sustentabilidade constituem-se em uma ferramenta significativa capaz de avaliar as formas, as condições e as consequências do modelo de desenvolvimento, vindo a servir como subsídio para minimizar o risco da tomada de decisão dos gestores, auxiliar na promoção de políticas públicas e ações para geração do desenvolvimento de forma sustentável. Ainda, sinalizam para uma nova forma de pensamento e conscientização da sociedade para o futuro do planeta em bases sustentáveis.

Ademais, iniciativas voltadas à criação de índices que mensuraram o grau de sustentabilidade de determinado espaço geográfico, favorece a prospecção de políticas que caminhem na direção do desenvolvimento sustentável e na participação da sociedade como ator principal nos processos de mudança (MACEDO et al., 2016).

Em suma, a importância das pesquisas que levam à construção de indicadores de sustentabilidade reside na capacidade de tentar responder a novas questões que vem emergindo nas áreas ambiental, social, demográfica, econômica, cultural e político-institucional, seja de um município, uma região, estado ou país.

\section{PROCEDIMENTOS METODOLÓGICOS}

A coleta de dados e a análise estão estruturadas a partir de um método proposto por Martins e Cândido (2008), o Índice de Desenvolvimento Sustentável para Municípios (IDSM). 
Esse método de avaliação dos níveis de sustentabilidade tem como objetivo a construção de um índice voltado para espaços geográficos, a partir da coleta, tratamento e análise de indicadores de sustentabilidade específicos. Para isso, utiliza um conjunto de seis dimensões (cultural, social, demográfica, político-institucional, ambiental e econômica).

O espaço geográfico de estudo é o Corede Produção, que está localizado na Região Funcional 9, no Estado do RS. Segundo a Bertê et al. (2015), o Corede Produção é composto por 21 municípios sendo: Almirante Tamandaré do Sul, Camargo, Carazinho, Casca, Ciríaco, Coqueiros do Sul, Coxilha, David Canabarro, Ernestina, Gentil, Marau, Mato Castelhano, Muliterno, Nova Alvorada, Passo Fundo, Pontão, Santo Antônio do Palma, Santo Antônio do Planalto, São Domingos do Sul, Vanini e Vila Maria. As variáveis foram pesquisadas para todos estes 21 municípios, para realizar o cálculo do IDSM do município de Passo Fundo-RS.

Para obter o cálculo do índice de modo que possibilite agregação adequada desses índices, é necessário estabelecer o tipo de relação que cada variável apresenta no contexto da sustentabilidade do município de Passo Fundo, se positivas ou negativas. A variável apresenta uma relação positiva quando verificado que, quanto maior o indicador melhor será o índice, e quanto menor o indicador, pior será o índice. A variável apresenta uma relação negativa quando verificado que, quanto maior o indicador, pior será o índice, quanto menor o indicador, melhor será o índice. Conforme mostra o Quadro 1.

Quadro 1 - Dimensões e variáveis da sustentabilidade

\begin{tabular}{|c|c|c|c|}
\hline \multicolumn{4}{|c|}{ Índices de Desenvolvimento Sustentável para Municípios } \\
\hline Dimensão & Variáveis & Alteração & Relação \\
\hline \multirow{7}{*}{$\begin{array}{c}\text { Dimensão } \\
\text { Cultural }\end{array}$} & Quantidade de bibliotecas & Mantido & $\mathrm{P}$ \\
\hline & Quantidade de museus & Mantido & $\mathrm{P}$ \\
\hline & Quantidade de ginásios de esportes e estádios & Mantido & $\mathrm{P}$ \\
\hline & Quantidade de cinemas & Mantido & $\mathrm{P}$ \\
\hline & Quantidade de Unidades de ensino superior & Mantido & $\mathrm{P}$ \\
\hline & Quantidade de teatros ou salas de espetáculos & Mantido & $\mathrm{P}$ \\
\hline & Quantidade de centros cultural & Mantido & $\mathrm{P}$ \\
\hline \multirow{17}{*}{ Dimensão Social } & Esperança de vida ao nascer & Mantido & $\mathrm{P}$ \\
\hline & Mortalidade infantil & Mantido & $\mathrm{N}$ \\
\hline & Prevalência da desnutrição total & Mantido & $\mathrm{N}$ \\
\hline & Imunização contra doenças infecciosas infantis & Mantido & $\mathrm{P}$ \\
\hline & Oferta de serviços básicos de saúde & Mantido & $\mathrm{P} / \mathrm{N}$ \\
\hline & Escolarização & Mantido & $\mathrm{P}$ \\
\hline & Alfabetização & Mantido & $\mathrm{P}$ \\
\hline & Escolaridade & Excluído & - \\
\hline & Analfabetismo funcional & Mantido & $\mathrm{N}$ \\
\hline & Transferência de benefícios sociais & Mantido & $\mathrm{N}$ \\
\hline & Adequação de moradia nos domicílios & Mantido & $\mathrm{P}$ \\
\hline & Mortalidade por homicídio & Mantido & $\mathrm{N}$ \\
\hline & Mortalidade por acidente de transporte & Mantido & $\mathrm{N}$ \\
\hline & Renda familiar per capita em salários mínimos & $\begin{array}{l}\text { Migrado de } \\
\text { Econômica }\end{array}$ & $\mathrm{N}$ \\
\hline & Índice de Gini de distribuição do rendimento & $\begin{array}{l}\text { Migrado de } \\
\text { Econômica }\end{array}$ & $\mathrm{N}$ \\
\hline & Razão de renda entre gêneros masculino e feminino & Incluído & $\mathrm{P}$ \\
\hline & Índice de Desenvolvimento Socioeconômico (Idese) & Incluído & $\mathrm{P}$ \\
\hline \multirow{3}{*}{$\begin{array}{c}\text { Dimensão } \\
\text { Demográfica }\end{array}$} & Taxa de crescimento da população & Mantido & $\mathrm{N}$ \\
\hline & Razão entre a população urbana e rural & Mantido & $\mathrm{P}$ \\
\hline & Densidade demográfica & Mantido & $\mathrm{N}$ \\
\hline
\end{tabular}


Quadro 1 - Dimensões e variáveis da sustentabilidade

Conclusão.

\begin{tabular}{|c|c|c|c|}
\hline \multicolumn{4}{|c|}{ Índices de Desenvolvimento Sustentável para Municípios } \\
\hline Dimensão & Variáveis & Alteração & Relação \\
\hline & Razão entre a população masculina e feminina & Mantido & $\mathrm{P}$ \\
\hline & Distribuição da população por faixa etária & Mantido & $\mathrm{P} / \mathrm{N}$ \\
\hline & Taxa de fecundidade & Incluído & $\mathrm{N}$ \\
\hline \multirow{7}{*}{$\begin{array}{l}\text { Dimensão } \\
\text { Político- } \\
\text { institucional }\end{array}$} & $\begin{array}{l}\text { Despesas por função: assistência social, educação, cultura, } \\
\text { urbanismo, habitação urbana, gestão ambiental, desporto e } \\
\text { lazer, saneamento urbano, saúde }\end{array}$ & Mantido & $\mathrm{P}$ \\
\hline & Acesso a serviço de telefonia fixa & Mantido & $\mathrm{P}$ \\
\hline & Participação nas eleições & Mantido & $\mathrm{P}$ \\
\hline & Número de conselhos municipais & Mantido & $\mathrm{P}$ \\
\hline & Número de acessos a justiça & Mantido & $\mathrm{P}$ \\
\hline & Transferências intergovernamentais da União & Mantido & $\mathrm{N}$ \\
\hline & Acesso público à Internet & Incluído & $\mathrm{P}$ \\
\hline \multirow{13}{*}{$\begin{array}{l}\text { Dimensão } \\
\text { Ambiental }\end{array}$} & $\begin{array}{l}\text { Qualidade das águas: aferição de cloro residual, de turbidez, de } \\
\text { coliformes totais }\end{array}$ & Mantido & $\mathrm{P} / \mathrm{N}$ \\
\hline & Tratamento das águas: tratada em ETAs e por desinfecção & Mantido & $\mathrm{P}$ \\
\hline & Consumo médio per capita de água & Mantido & $\mathrm{N}$ \\
\hline & Acesso ao sistema de abastecimento de água & Mantido & $\mathrm{P}$ \\
\hline & Tipo de esgotamento sanitário por domicílio & Excluído & - \\
\hline & Acesso à coleta de lixo urbano e rural & Mantido & $\mathrm{P}$ \\
\hline & Acesso à sistema de esgotamento sanitário & Incluído & $\mathrm{P}$ \\
\hline & Área da terra ocupada com pastagens e lavouras & Incluído & $\mathrm{N}$ \\
\hline & Área da terra ocupada com matas e florestas & Incluído & $\mathrm{P}$ \\
\hline & Uso de agrotóxicos & Incluído & $\mathrm{N}$ \\
\hline & Controle biológico de pragas e/ou doenças em vegetais & Incluído & $\mathrm{P}$ \\
\hline & Uso de agricultura orgânica & Incluído & $\mathrm{P}$ \\
\hline & Sistema de plantio direto na palha & Incluído & $\mathrm{P}$ \\
\hline \multirow{8}{*}{$\begin{array}{l}\text { Dimensão } \\
\text { Econômica }\end{array}$} & Produto Interno bruto per capita & Mantido & $\mathrm{P}$ \\
\hline & Participação da indústria no PIB & Mantido & $\mathrm{P}$ \\
\hline & Saldo da balança comercial & Excluído & - \\
\hline & Renda per capita & Excluído & - \\
\hline & Rendimentos provenientes do trabalho & Mantido & $\mathrm{P}$ \\
\hline & Participação da agropecuária no PIB & Incluído & $\mathrm{P}$ \\
\hline & Participação de comércio/serviços no PIB & Incluído & $\mathrm{P}$ \\
\hline & Particip & Incluído & $\mathrm{N}$ \\
\hline
\end{tabular}

Fonte: Adaptado de Martins e Cândido (2008)

Legenda: (P) - Relação Positiva; (N) - Relação Negativa; (P/N) - Relação Positiva e Negativa

Portanto, foram catalogados os dados respectivos de cada uma das variáveis selecionadas, tanto para o município de Passo Fundo, como para os demais municípios do Corede Produção. Ainda que somente seja apresentado os índices do município de Passo Fundo, a catalogação dos demais é necessária para a efetivação do cálculo da transformação das variáveis em índices, uma vez que o índice apresentado é resultado da comparação com os demais municípios do Corede Produção.

Como as variáveis apresentam diferentes unidades de medida, as mesmas foram transformadas em índices, que possibilitaram a agregação nas respectivas dimensões para a estimação do IDSM. O procedimento utilizado ajusta os valores das variáveis numa escala com variação, cujo valor mínimo é 0 (zero) e o valor máximo é 1 (um). Assim, os índices apresentarão valores com variação entre $0-1$. 
Definida a relação de cada variável, a operacionalização para o cálculo do índice é realizada a partir de fórmulas que reconhecem essas relações e permitem a análise da sustentabilidade através da agregação de todos os índices. Então:

Se a relação é positiva:

$\mathrm{I}=(\mathrm{x}-\mathrm{m}) /(\mathrm{M}-\mathrm{m})$

Em que:

I - índice resultante do valor de $\mathrm{x}$, para o município analisado;

$\mathrm{x}$ - valor da variável para o município analisado;

m - valor mínimo da variável identificado entre os municípios do Corede Produção;

M - valor máximo da variável, identificado entre os demais municípios do Corede Produção.

Após a transformação das variáveis em índices, foi realizada a agregação desses índices por tema e dimensão, através da média aritmética, chegando-se ao IDSM cultural, social, demográfico, político-institucional, ambiental e econômico do município de Passo Fundo-RS. O cálculo do índice de cada tema é o resultado da média aritmética do indicador de cada variável que compõe o tema analisado. O cálculo do índice de cada dimensão é o resultado da média aritmética dos índices de cada tema que compõe a dimensão analisada. E por fim, o IDSM final foi calculado através da média aritmética dos IDSMs de cada dimensão.

Quadro 2 - Classificação e representação dos índices em níveis de sustentabilidade

\begin{tabular}{|c|c|c|}
\hline Índice 0-1 & Coloração & Nível de Sustentabilidade \\
\hline $0,0000-0,2500$ & & Crítico \\
\hline $0,2501-0,5000$ & & Alerta \\
\hline $0,5001-0,7500$ & & Aceitável \\
\hline $0,7501-1,0000$ & & Ideal \\
\hline
\end{tabular}

Fonte: Martins e Cândido (2008)

Para a classificação desses índices referentes a cada variável, ao IDSM das dimensões e ao IDSM final, a metodologia apresenta um conjunto de cores que correspondem a uma escala definida, que caracteriza os níveis de sustentabilidade, conforme mostrado no Quadro 2. Os resultados também são apresentados em forma de um gráfico de radar.

Nessa classificação (Quadro 2) o índice se torna mais sustentável ao se aproximar de 1 e menos sustentável ao se aproximar de 0. Ainda que na prática essas dimensões estão, em maior ou menor grau relacionadas, para efeito de análise, elas são apresentadas de forma isolada, para cada dimensão e tema a partir da agregação das variáveis, também para o IDSM final.

Os dados dos indicadores referentes aos municípios foram obtidos, no ano de 2017, nas principais bases de dados e portais institucionais - IBGE (Censo Demográfico 2000/2010; Censo Agropecuário 2006), Ministério da Educação, Atlas do Desenvolvimento Humano, Portal da Transparência, FEE, Departamento de Informática do Sistema Único de Saúde (DATASUS), Tribunal Regional Eleitoral (TRE/RS), Tribunal de Contas do Estado do RS (TCE), Sistema Nacional de Informações sobre Saneamento (SNIS) e IPEADATA - em que

Revista Desenvolvimento Socioeconômico em debate v.7 n.1 (2021) 
utilizou-se o ano mais recente disponível, o período dos dados variou entre os anos de 2000 a 2016.

\subsection{Caracterização do município de Passo Fundo-RS}

Passo Fundo é um município brasileiro da região Sul, localizado na Mesorregião do Noroeste Rio-grandense, interior do estado do Rio Grande do Sul-RS. É a maior cidade do Norte do Estado, sendo considerada cidade média e capital regional da Região Funcional 9 (composta pelo Corede Produção e outros 5 Coredes). Com população, em 2017, de 199.346 habitantes, entretanto, Passo Fundo aparenta ser bem mais populosa, por ser uma cidade universitária e polo comercial do norte do estado, o que implica em grande fluxo de pessoas diariamente que transitam pela cidade em busca de diversos serviços. Possui área de $783,4 \mathrm{~km}^{2}$ (2015), e um grande número de edifícios, sendo uma das cidades mais densas do Estado. O PIB do município, em 2015, foi de R\$ 7.817.961,53 (FEE, 2019).

Em termos econômicos, na composição do PIB do município, o setor dos serviços tem maior participação, seguido do setor da indústria e do agronegócio (FEE, 2014). O município se caracteriza por ser um forte polo no setor em saúde e também, é polo de referência em educação universitária. A produção e a renda gerada no município estão centradas nos setores do comércio, sobretudo, o varejista e de serviços, responsável pela maior parte dos empregos gerados localmente.

\section{NÍVEIS DE SUSTENTABILIDADE DO MUNICÍPIO DE PASSO FUNDO-RS}

Neste capítulo serão apresentados os resultados obtidos do IDSM em suas seis dimensões: cultural, social, demográfica, político-institucional, ambiental e econômica, para o município de Passo Fundo-RS.

\subsection{Descrição e análise da dimensão cultural}

A infraestrutura relacionada à cultura é uma importante condição para que sejam alcançados os objetivos em termos de sustentabilidade cultural de uma determinada região, devendo ser complementados por programas e projetos culturais que tenham capacidade de atrair e envolver a população nas atividades culturais, artísticas e intelectuais (MARTINS; CÂNDIDO, 2008). A dimensão cultural diz respeito à quantidade de equipamentos culturais existentes nos municípios do Corede Produção. Nesta pesquisa, foram consideradas apenas a existência e a quantidade de equipamentos culturais, não indicando o fluxo nem uma avaliação qualitativa dessas atividades.

De acordo com indicadores que compõem os respectivos temas (Quadro 3), há que se destacar dois indicadores (Estádios e ginásios de esportes; bibliotecas) que em maior ou menor grau, impactam os temas Conhecimento $(0,7500)$, considerado aceitável, de acordo com o método e o tema Esporte e Lazer $(0,8889)$, considerado ideal.

Neste contexto, a sustentabilidade da dimensão cultural mostra-se com nível de sustentabilidade ideal $(0,8195)$ - média dos índices dos temas. Convém ressaltar que a possível razão do indicador "Bibliotecas" estar classificado como nível crítico deve-se ao fato de município possuir apenas uma biblioteca municipal, de livre acesso à população (com base nos dados secundários), não havendo estrutura para atendê-los. Tendo em vista que, a quantidade de bibliotecas apresenta uma relação positiva com níveis de educação, um forte influenciador 
no desenvolvimento sustentável, ele é importante por possibilitar novas oportunidades e mais equidade social através do acesso às informações e conhecimentos necessários ao desenvolvimento profissional e pessoal do cidadão (MARTINS; CÂNDIDO, 2008).

Quadro 3 - Índices dos indicadores da dimensão cultural do município de Passo Fundo-RS

\begin{tabular}{|c|c|c|c|c|}
\hline Dimensão & Tema & Indicador & Índice & $\begin{array}{c}\text { Índice de Média } \\
\text { Aritmética dos temas }\end{array}$ \\
\hline \multirow{7}{*}{ Cultural } & \multirow{4}{*}{ Conhecimento } & Bibliotecas & 0,0000 & \multirow{4}{*}{0,7500} \\
\hline & & Museus & 1,0000 & \\
\hline & & Centros culturais & 1,0000 & \\
\hline & & $\begin{array}{c}\text { Unidades de ensino superior } \\
\text { (UES) }\end{array}$ & 1,0000 & \\
\hline & \multirow{3}{*}{ Esporte e lazer } & Estádios e ginásios de esportes & 0,6667 & \multirow{3}{*}{0,8889} \\
\hline & & Cinemas & 1,0000 & \\
\hline & & Teatros ou salas de espetáculos & 1,0000 & \\
\hline
\end{tabular}

Fonte: Autoria própria (2017)

Legenda: Crítico $\square$ Alerta $\square$ Aceitável $\square \quad$ Ideal

Por outro lado, considerando o índice nos demais indicadores da dimensão, o município de Passo Fundo tem influência significativa como polo educacional, por meio da Universidade de Passo Fundo e demais Instituições de Ensino Superior, que abrangem grande parte da população da Região da Produção. A disponibilidade de museus, centros culturais e teatro contribuem de maneira expressiva, além de ser o único município do Corede Produção a dispor de cinema, que também atrai a população da região.

Diferentemente do cenário dos municípios de Mato Grosso, apresentado no estudo de Macedo et al. (2016), em que avaliaram os níveis de sustentabilidade dos municípios do Estado de Mato Grosso mediante o IDSM. Nenhum município apresentou situação ideal, 1,42\% apresentou situação de alerta e $97,87 \%$ situação crítica. Os autores afirmam que esse resultado aponta a premência de políticas direcionadas ao desenvolvimento cultural da população matogrossense. Com isso, acarreta em consequências negativas ao longo prazo, pois uma sociedade sem aparato cultural pode estar sujeita a desigualdades regionais, refletidas em miséria, violência, baixo nível educacional entre outros.

O estudo de Souza et al. (2013), que analisaram o nível de desenvolvimento sustentável das capitais brasileiras, a partir do IDSM. Os autores evidenciaram também uma situação crítica nesta dimensão, pois identificaram situação crítica em quase todas as capitais brasileiras, ou seja 3,70\% estão classificadas no nível ideal e aceitável, 18,52\% em nível alerta e 74,07\% encontram-se no nível de sustentabilidade crítica.

\subsection{Descrição e análise da dimensão social}

A dimensão social possibilita um conjunto de informações sobre os aspectos sociais que influenciam na qualidade de vida da população e no acesso de forma igualitária aos serviços oferecidos à população. Trata-se de informações que contribuem no sentido de respaldar possíveis orientações para a formulação e implementação de políticas sociais para o município de Passo Fundo que propiciem maior qualidade de vida da população, em uma perspectiva mais ampla (MARTINS; CÂNDIDO, 2008).

Analisando os valores dos indicadores sistematizados (Quadro 4) há que se destacar dois índices críticos (Índice de Gini da distribuição de renda - 0,1905; Mortalidade por homicídios 
- 0,1840) que impactam o tema Equidade de Renda, no entanto, este tema ainda apresenta nível de sustentabilidade aceitável $(0,5697)$. Assim como, impacta no tema Segurança, que apresenta o nível de sustentabilidade em alerta $(0,4505)$.

Outro tema que também se apresentou em nível de sustentabilidade em alerta é o Idese ${ }^{4}$, frente aos demais municípios do Corede Produção. No entanto, na classificação desse índice, Passo Fundo se classifica em médio desenvolvimento com índice de 0,771 em 2013 (dados secundários da pesquisa). Os demais temas como se pode ver no Quadro 4, apresentam desempenho satisfatório.

Quadro 4 - Índices dos indicadores da dimensão social do município de Passo Fundo-RS

\begin{tabular}{|c|c|c|c|c|}
\hline Dimensão & Tema & Indicador & Índice & $\begin{array}{c}\text { Índice de Média } \\
\text { Aritmética dos temas }\end{array}$ \\
\hline \multirow{16}{*}{ Social } & \multirow{4}{*}{$\begin{array}{l}\text { Equidade de } \\
\text { Renda }\end{array}$} & $\begin{array}{l}\text { Índice de Gini da distribuição de } \\
\text { renda }\end{array}$ & 0,1905 & \multirow{4}{*}{0,5697} \\
\hline & & $\begin{array}{c}\text { Renda familiar per capita (até } 1 / 2 \\
\text { SM) }\end{array}$ & 0,6206 & \\
\hline & & Transferência de benefícios sociais & 0,8156 & \\
\hline & & $\begin{array}{l}\text { Razão entre rendas masculina e } \\
\text { feminina (menor/maior) }\end{array}$ & 0,6522 & \\
\hline & \multirow[b]{2}{*}{$\begin{array}{l}\text { Cuidado com a } \\
\text { Saúde }\end{array}$} & Esperança de vida ao nascer & 0,5335 & \multirow[b]{2}{*}{0,6394} \\
\hline & & $\begin{array}{l}\text { Oferta de serviços básicos de } \\
\text { saúde }\end{array}$ & 0,7453 & \\
\hline & \multirow{3}{*}{$\begin{array}{c}\text { Atenção à Saúde } \\
\text { da } \\
\text { Criança }\end{array}$} & Mortalidade infantil & 0,7998 & \multirow{3}{*}{0,7402} \\
\hline & & Prevalência de desnutrição total & 0,8881 & \\
\hline & & $\begin{array}{l}\text { Imunização contra doenças } \\
\text { infecciosas infantis }\end{array}$ & 0,5327 & \\
\hline & \multirow{3}{*}{ Educação } & Escolarização & 0,9610 & \multirow{3}{*}{0,9581} \\
\hline & & Alfabetização & 1,0000 & \\
\hline & & Analfabetismo funcional & 0,9134 & \\
\hline & \multirow[t]{2}{*}{ Segurança } & $\begin{array}{l}\text { Mortalidade por acidentes de } \\
\text { transporte }\end{array}$ & 0,7170 & \multirow[t]{2}{*}{0,4505} \\
\hline & & Mortalidade por homicídios & 0,1840 & \\
\hline & Habitação & Adequação de moradias & 0,7050 & 0,7050 \\
\hline & $\begin{array}{c}\text { Desenvolvimento } \\
\text { socioeconômico }\end{array}$ & Idese & 0,3469 & 0,3469 \\
\hline
\end{tabular}

Fonte: Autoria própria (2017)

Legenda: Crítico $\square$ Alerta $\square$ Aceitável $\square \quad$ Ideal

Em síntese, a sustentabilidade da dimensão social apresentou um índice de $(0,6300)$, que de acordo com a classificação considerada no método, obteve um nível de sustentabilidade aceitável. No tema Equidade e Renda (nível aceitável) demonstra a relevância de implementação de possíveis ações que devessem subsidiar estratégias de combate à pobreza e a redução das desigualdades. Já o tema Segurança tem relação com a alta criminalidade existente no município, causando insegurança da população, além de custos sociais e

\footnotetext{
${ }^{4}$ O Índice de Desenvolvimento Socioeconômico (IDESE), elaborado pela Fundação de Economia e Estatística (FEE), é um índice sintético que tem por objetivo medir o grau de desenvolvimento dos municípios do Rio Grande do Sul. Para cada uma das variáveis componentes dos blocos Saúde, Educação e Renda, é calculado um Índice. Considera-se a classificação do índice em Alto (acima de 0,800), Médio (entre 0,500 e 0,799) e Baixo (abaixo de 0,499) nível de desenvolvimento (BERTÊ et al., 2015).
} 
econômicos, pois além da vida perdida, muitas vezes, prematuramente gera sequelas emocionais as famílias das vítimas, elevando os custos hospitalares.

No estudo de Macedo et al. (2016), apenas Cuiabá (capital) foi classificada com nível ideal de sustentabilidade $(0,71 \%)$ e $84,40 \%$ dos municípios se encontram com classificação aceitável de sustentabilidade, indicando que o Estado de Mato Grosso possui potencial de convergência para estágio ideal de sustentabilidade no âmbito social, dado que apenas 14,89\% dos municípios apresentaram estado de alerta e nenhum apresentou nível crítico.

No estudo referentes às capitais brasileiras, Souza et al. (2013) verificaram que apenas 6,9\% das capitais apresentam nível ideal de sustentabilidade social, 44,83\% aceitável, 44,83\% de alerta e nenhuma apresenta nível crítico.

\subsection{Descrição e análise da dimensão demográfica}

A dimensão demográfica gera um conjunto de informações produzidas por índices demográficos que oferecem subsídios para maior controle populacional, equilíbrio entre a população masculina e feminina, distribuição da população urbana e rural de forma compatível com a realidade local, bem como, adequação no nível de concentração da população (MARTINS; CÂNDIDO, 2008). O grupo de índices que compõe essa dimensão corresponde a aspectos relacionados à população, conforme o demonstrado no Quadro 5.

O tema Dinâmica Populacional que representa a dimensão demográfica apresentou nível alerta de sustentabilidade, com índice de 0,2947, derivado, em larga medida de um conjunto de indicadores (Quadro 5) que apresentam nível crítico.

Quadro 5 - Índices dos indicadores da dimensão demográfica do município de Passo Fundo-RS

\begin{tabular}{|c|c|c|c|c|}
\hline Dimensão & Tema & Indicador & Índice & $\begin{array}{c}\text { Índice de Média } \\
\text { Aritmética dos temas }\end{array}$ \\
\hline \multirow{6}{*}{ Demográfica } & \multirow{6}{*}{$\begin{array}{c}\text { Dinâmica } \\
\text { Populacional }\end{array}$} & Taxa de fecundidade & 0,4444 & \multirow{6}{*}{0,2947} \\
\hline & & $\begin{array}{c}\text { Distribuição da população por faixa } \\
\text { etária }\end{array}$ & 0,7850 & \\
\hline & & Densidade demográfica & 0,0000 & \\
\hline & & Taxa de crescimento da população & 0,3463 & \\
\hline & & Razão entre população Rural/Urbana & 0,0104 & \\
\hline & & $\begin{array}{c}\text { Razão entre população } \\
\text { masculina/feminina }\end{array}$ & 0,1818 & \\
\hline
\end{tabular}

Fonte: Autoria própria (2017)

Legenda: Crítico $\square \quad$ Alerta $\square$ Aceitável $\square \quad$ Ideal

De um modo geral, em nível de Corede Produção, o município de Passo Fundo apresenta uma densidade populacional alta, e com indicador da taxa de crescimento em alerta. Essa configuração tende a demandar infraestrutura de maneira a propiciar condições adequadas de vida com moradia, educação, saúde e, principalmente, a preservação do meio ambiente, portanto, requerendo maior volume de recursos para atender toda a população.

Chama-se atenção, também para o desequilíbrio entre a população rural e urbana, havendo migração expressiva da população rural para a cidade; e, para o desequilíbrio entre a população masculina e feminina. Evidencia-se, portanto, a necessidade de direcionar maior 
atenção a dimensão demográfica voltada para o controle populacional do município de Passo Fundo.

Analisando os dados da pesquisa de Macedo et al. (2016), nenhum município matogrossense apresentou nível ideal de sustentabilidade, 34,04\% enquadraram-se como aceitáveis, $65,96 \%$ indicaram estar em nível de alerta e nenhum em estado crítico de sustentabilidade. Os autores evidenciaram que o nível de alerta demonstra a distribuição desigual populacional do Estado de Mato Grosso, dado a maior concentração do contingente de habitantes nas zonas geográficas mais produtivas.

Já no estudo de Souza et al. (2013), 20,00\% das capitais brasileiras apresenta nível ideal; nenhuma apresenta nível aceitável; 20,00\% nível de alerta e 60\% apresenta situação crítica.

\subsection{Descrição e análise da dimensão político-institucional}

A dimensão político-institucional diz respeito às despesas, participação política, capacidade e esforço desprendido para as mudanças requeridas para a implementação do desenvolvimento sustentável no município de Passo Fundo. Esses índices quando analisados em conjunto permitem uma avaliação dos níveis de sustentabilidade, tendo como contribuição um conjunto de informações que servirão de fio condutor para a busca de alternativas para o desenvolvimento sustentável nessa localidade (MARTINS; CÂNDIDO, 2008).

Quadro 6 - Índices dos indicadores da dimensão político-institucional do município de Passo Fundo-RS

\begin{tabular}{|c|c|c|c|c|}
\hline Dimensão & Tema & Indicador & Índice & $\begin{array}{c}\text { Índice de Média } \\
\text { Aritmética dos } \\
\text { temas }\end{array}$ \\
\hline \multirow{7}{*}{$\begin{array}{c}\text { Político- } \\
\text { institucional }\end{array}$} & \multirow{4}{*}{$\begin{array}{l}\text { Acesso pela } \\
\text { População }\end{array}$} & Acesso a serviços de telefonia & 0,8064 & \multirow{4}{*}{0,6747} \\
\hline & & Acesso público à Internet & 0,8133 & \\
\hline & & Acessos à justiça & 1,0000 & \\
\hline & & Comparecimento nas eleições & 0,0789 & \\
\hline & \multirow{3}{*}{$\begin{array}{l}\text { Capacidade } \\
\text { Institucional }\end{array}$} & $\begin{array}{l}\text { Despesa por função (Cultura, } \\
\text { Urbanismo, Gestão Ambiental, } \\
\text { Desporto e Lazer) }\end{array}$ & 0,9405 & \multirow{3}{*}{0,9802} \\
\hline & & $\begin{array}{l}\text { Transferências de recursos da } \\
\text { União }\end{array}$ & 1,0000 & \\
\hline & & Número de Conselhos Municipais & 1,0000 & \\
\hline
\end{tabular}

Fonte: Autoria própria (2017)

Legenda: Crítico $\square \quad$ Alerta $\square \quad$ Aceitável $\square \quad$ Ideal

De um modo geral a sustentabilidade da dimensão político-institucional apresentou nível ideal de sustentabilidade (Quadro 6), com índice da média dos temas de (0,8275). O tema Acesso pela População, em nível aceitável, chama atenção para o indicador comparecimento nas eleições $(0,0789)$, em nível crítico, onde muitos dos cidadãos deixam de exercer o direito ao voto, que tem relação direta com a democracia.

Quanto aos demais temas, observa-se ótimo desempenho, em nível ideal, em todos os indicadores. O município de Passo Fundo, com o volume baixo de transferências intergovernamentais, o que pode demonstrar um menor risco de vulnerabilidade em relação ao desenvolvimento sustentável pela dependência de recursos externos para a manutenção de suas funções. E por fim, a existência de maior número de conselhos municipais expressa a mobilização da sociedade pela participação na vida institucional do município. 
Ao contrário de Passo Fundo, nenhum município do Mato Grosso apresentou estado ideal, apenas 1,42\% revelou estado aceitável, 78,72\% dos municípios apresentaram estado de alerta e $19,86 \%$ revelou estado crítico. Os autores colocam que esse resultado demonstra a precariedade das instituições dos municípios mato-grossenses, em especial, no que concerne a distribuição de despesas com investimentos, a baixa participação política da população e a falta de concessão dos meios necessários para o exercício da cidadania e da justiça social (MACEDO et al., 2016).

No estudo de Souza et al. (2013), o IDSM político-institucional revelou uma situação de alerta em quase todas as capitais do país. Nenhuma das capitais apresentou a classificação ideal, e apenas 13,33\% encontra-se em nível de sustentabilidade aceitável. Enquanto que $60,00 \%$ apresentaram nível alerta e 20,00\% nível crítico.

\subsection{Descrição e análise da dimensão ambiental}

A dimensão ambiental corresponde aos aspectos relacionados ao uso dos recursos naturais e à degradação do ambiente, e está relacionada aos objetivos de preservação e conservação do meio ambiente, considerados fundamentais para manter a qualidade de vida e ambiental das atuais e futuras gerações (MARTINS; CÂNDIDO, 2008).

O conjunto de informações produzidas por esses índices ambientais oferece subsídios para compreender aspectos relevantes do processo de degradação ambiental. Diante dessas informações, torna-se possível estabelecer políticas que propiciam o desenvolvimento das atividades produtivas sem comprometer as gerações futuras. Esses aspectos refletem as condições básicas necessárias para que a população possa viver com mais qualidade de vida e ambiental (MARTINS; CÂNDIDO, 2008).

No que concerne à dimensão ambiental (Quadro 7), um número maior de indicadores apresentou índices críticos (Pastagens e lavouras - 0,1893; Matas e florestas - 0,0927; Controle biológico de pragas e/ou doenças em vegetais - 0,1510 e Sistema de plantio direto na palha 0,0000) gerando uma média de sustentabilidade da dimensão ambiental $(0,5492)$, passível de classificação como nível aceitável de sustentabilidade, no entanto, em um limite crítico e um nível de alerta.

No tema Água Potável, em nível aceitável, chama atenção o indicador volume da água tratada que se classificou em nível alerta, onde o Tratamento da água em Estações de Tratamentos (ETAs) gerou nível ideal máximo e o Tratamento da água por simples desinfecção gerou índice crítico mínimo. Isto é, Passo Fundo tem seu volume de água tratado apenas em ETAs (Quadro 7).

O tema Uso da Terra se apresentou por completo em nível crítico, considerando que a Região da Produção tem uma dinâmica forte e crescente em relação a agropecuária e as indústrias, com várias cadeias agroindustriais dominantes presentes como a produção de soja, milho, trigo, leite e criação de aves e suínos. Isso explica a grande parte da área dos estabelecimentos rurais de Passo Fundo sendo composta por pastagens e lavouras (FINAMORE, 2010).

Quadro 7 - Índices dos indicadores da dimensão ambiental do município de Passo Fundo-RS

\begin{tabular}{|c|c|c|c|c|}
\hline Dimensão & Tema & Indicador & Índice & $\begin{array}{c}\text { Índice de Média } \\
\text { Aritmética dos } \\
\text { temas }\end{array}$ \\
\hline Ambiental & & Acesso a esgotamento sanitário & 0,8980 & 0,9592 \\
\hline
\end{tabular}




\begin{tabular}{|c|c|c|c|}
\hline Saneamento & $\begin{array}{l}\text { Acesso ao sistema de } \\
\text { abastecimento de água }\end{array}$ & 0,9797 & \\
\hline de Lixo & $\begin{array}{c}\text { Acesso a serviço de coleta de lixo } \\
\text { doméstico }\end{array}$ & 1,0000 & \\
\hline \multirow{3}{*}{ Água Potável } & Volume da água tratada & 0,5000 & \multirow{3}{*}{0,6156} \\
\hline & Qualidade das águas & 0,5341 & \\
\hline & $\begin{array}{l}\text { Consumo médio per capita de } \\
\text { água }\end{array}$ & 0,8128 & \\
\hline \multirow{2}{*}{ Uso da Terra } & Pastagens e Lavouras & 0,1893 & \multirow{2}{*}{0,1410} \\
\hline & Matas e florestas & 0,0927 & \\
\hline \multirow{4}{*}{$\begin{array}{l}\text { Práticas } \\
\text { Agrícolas }\end{array}$} & Uso de agrotóxicos & 0,7726 & \multirow{4}{*}{0,4809} \\
\hline & $\begin{array}{l}\text { Controle biológico de pragas e/ou } \\
\text { doenças em vegetais }\end{array}$ & 0,1510 & \\
\hline & Uso de agricultura orgânica & 1,0000 & \\
\hline & Sistema de plantio direto na palha & 0,0000 & \\
\hline
\end{tabular}

Fonte: Autoria própria (2017)

Legenda: Crítico $\square$ Alerta $\square$ Aceitável $\square \quad$ Ideal

No entanto, podem ocorrer fortes pressões pelo uso da terra com a exploração agropecuária com fins econômicos sem a preocupação com a degradação ambiental. $\mathrm{O}$ município apresentou menor área dos estabelecimentos rurais com matas e florestas, gerando um estado crítico, sendo que o crescimento das áreas de matas e florestas contribui para o maior equilíbrio da biodiversidade.

Por fim, no último tema Práticas Agrícolas, classificado em nível alerta, chama a atenção para o indicador de Sistema de plantio direto, em que Passo Fundo apresenta a menor percentagem de estabelecimentos que aderem ao plantio direto na palha $(68,3 \%)$, que visa diminuir o impacto da agricultura e das máquinas agrícolas sobre o solo, em comparação com os demais municípios do Corede Produção o que justifica o fato do indicador ficar zerado.

$\mathrm{O}$ indicador de Controle biológico também se mostra em estado crítico, e com a necessidade talvez de maior disseminação de informação e conhecimento sobre a prática, que controla as pragas agrícolas e os insetos transmissores de doenças a partir do uso de seus inimigos naturais. Por outro lado, os indicadores: Uso de agricultura orgânica e Uso de agrotóxicos se mostraram positivos, em estado ideal. Passo Fundo apresenta o maior número de estabelecimentos rurais que praticam a agricultura orgânica e apresenta, relativamente, um baixo número de estabelecimentos que fazem uso dos agrotóxicos em relação aos demais municípios.

Na pesquisa de Macedo et al. (2016), 2,13\% dos municípios apresentou nível ideal de sustentabilidade ambiental, 64,54\% obtiveram classificação aceitável, 32,62\% de alerta e 0,71\% apresentaram nível crítico. Assim, o Estado de Mato Grosso, apesar de algumas deficiências regionais, tem uma performance de conservação do meio ambiente aceitável na faixa dos $64,54 \%$.

O IDSM ambiental da pesquisa de Souza et al. (2013), revelou uma situação de alerta em quase todas as capitais do país. Nenhuma apresentou a classificação ideal e crítico, ou seja $14,81 \%$ encontram-se no nível de sustentabilidade aceitável e 85,19\% das capitais apresentam nível de alerta.

\subsection{Descrição e análise da dimensão econômica}

A dimensão econômica gera um conjunto de informações relacionadas aos objetivos ligados ao desempenho econômico e financeiro e aos rendimentos da população. Tais 
informações são significativa relevância para a implementação do desenvolvimento sustentável, pois pode orientar as decisões e formulação de políticas públicas com capacidade de gerar projetos que propiciem melhorias na qualidade de vida da população (MARTINS; CÂNDIDO, 2008).

Nesta dimensão, conforme Quadro 8, chama atenção um indicador considerado crítico (Participação da agropecuária no PIB - 0,0000) e dois indicadores em nível de alerta de sustentabilidade (Participação da indústria no PIB - 0,3180 e Renda proveniente do trabalho $0,3469)$.

Quadro 8 - Índices dos indicadores da dimensão econômica do município de Passo Fundo-RS

\begin{tabular}{|c|c|c|c|c|}
\hline Dimensão & Tema & Indicador & Índice & $\begin{array}{c}\text { Índice de Média } \\
\text { Aritmética dos temas }\end{array}$ \\
\hline \multirow{6}{*}{ Econômica } & \multirow{5}{*}{$\begin{array}{c}\text { Produto } \\
\text { Interno Bruto } \\
\text { - PIB }\end{array}$} & Participação da indústria no PIB & 0,3180 & \multirow{5}{*}{0,5628} \\
\hline & & $\begin{array}{l}\text { Participação da agropecuária no } \\
\text { PIB }\end{array}$ & 0,0000 & \\
\hline & & $\begin{array}{l}\text { Participação da administração } \\
\text { pública no PIB }\end{array}$ & 0,9682 & \\
\hline & & $\begin{array}{c}\text { Participação de comércio/serviços } \\
\text { no PIB }\end{array}$ & 1,0000 & \\
\hline & & PIB per capita & 0,5276 & \\
\hline & $\begin{array}{c}\text { Trabalho e } \\
\text { Renda }\end{array}$ & Renda proveniente do trabalho & 0,3469 & 0,3469 \\
\hline
\end{tabular}

Fonte: Autoria própria (2017)

Legenda: Crítico $\square$ Alerta $\square \quad$ Aceitável $\square \quad$ Ideal

Em uma perspectiva mais ampla, a sustentabilidade da dimensão econômica apresentou um índice de $(0,4549)$, nível de sustentabilidade em alerta. No município de Passo Fundo, a análise demonstra maior participação no PIB através do comércio e serviços. O índice crítico da Participação da agropecuária no PIB do município é em virtude dos municípios menos populosos do Corede Produção deterem da maior parte de sua economia proveniente da agropecuária. Ou seja, a Região da Produção tem eixo urbano e industrializado mais representado pelos municípios de Carazinho, Marau e Passo Fundo e os demais municípios têm a agropecuária como base econômica (FINAMORE, 2010).

Nota-se a necessidade de maior atenção à indústria, no sentido de intensificar o crescimento da economia e para a geração de empregos. O tema Trabalho e Renda, em nível alerta, demonstra a necessidade de atenção para a geração de renda da população para sua sobrevivência através do trabalho, que por sua vez, reduz a dependência em relação às transferências governamentais, ao mesmo tempo em que promove o desenvolvimento local.

Macedo et al. (2016) evidenciaram que nenhum município mato-grossense apresentou resultado ideal, apenas 7,09\% enquadraram-se no nível aceitável de sustentabilidade, 78,72\% encontram-se em estado de alerta e $19,15 \%$ em estado crítico. Afirmam que os municípios apresentam disparidades em seu desempenho econômico.

Souza et al. (2013) identificaram que 33,33\% das capitais brasileiras apresentam nível ideal de sustentabilidade, 8,33\% nível aceitável, 16,67\% situação de alerta e 41,67\% nível crítico. Diante desses resultados, os autores constataram que a maioria das capitais apresenta nível de sustentabilidade desfavorável, comprometendo a qualidade de vida da população. 


\subsection{Síntese do IDSM do município de Passo Fundo-RS}

Com o índice dos temas calculados foi possível obter a média do índice para cada dimensão da sustentabilidade. Como observa-se no Quadro 9, estão agrupadas as seis dimensões, onde a maioria das dimensões se mostraram favoráveis para a sustentabilidade, não havendo nenhuma dimensão em estado crítico.

Quanto à análise dos temas, entende-se que os agentes no município de Passo Fundo, tanto públicos como privados precisam ficar atentos e desenvolver soluções para a melhoria dos índices voltados para os temas uso da terra, dinâmica populacional, trabalho e renda, segurança e práticas agrícolas nos estabelecimentos rurais.

O tema do Desenvolvimento socioeconômico se classificou em nível alerta em relação aos demais municípios do Corede Produção. Em termos mais abrangentes, o município de Passo Fundo pode ser considerado como de médio desenvolvimento, conforme a classificação do Idese (BERTÊ et al., 2015), que pode ser considerado um índice bom, mas o importante para um município é que ele possa alcançar altos índices de desenvolvimento, o que é possível a partir de esforços conjuntos de todas as esferas institucionais públicas e privadas, bem como da população em geral.

Quadro 9 - Índices dos temas, dimensões e IDSM final do município de Passo Fundo-RS

\begin{tabular}{|c|c|c|c|}
\hline Dimensão & Tema & Índice dos temas & $\begin{array}{l}\text { Índice das } \\
\text { Dimensões }\end{array}$ \\
\hline \multirow{2}{*}{ Cultural } & Conhecimento & 0,7500 & \multirow{2}{*}{0,8195} \\
\hline & Esporte e lazer & 0,8889 & \\
\hline \multirow{7}{*}{ Social } & Equidade de Renda & 0,5697 & \multirow{7}{*}{0,6300} \\
\hline & Cuidado com a Saúde & 0,6394 & \\
\hline & Atenção à saúde da Criança & 0,7402 & \\
\hline & Educação & 0,9581 & \\
\hline & Segurança & 0,4505 & \\
\hline & Habitação & 0,7050 & \\
\hline & Desenvolvimento socioeconômico & 0,3469 & \\
\hline Demográfica & Dinâmica Populacional & 0,2947 & 0,2947 \\
\hline \multirow{2}{*}{ Político-institucional } & Acesso pela População & 0,6747 & \multirow{2}{*}{0,8275} \\
\hline & Capacidade Institucional & 0,9802 & \\
\hline \multirow{4}{*}{ Ambiental } & Saneamento básico e coleta de lixo & 0,9592 & \multirow{4}{*}{0,5492} \\
\hline & Água potável & 0,6156 & \\
\hline & Uso da terra & 0,1410 & \\
\hline & $\begin{array}{c}\text { Práticas agrícolas nos estabelecimentos } \\
\text { rurais } \\
\end{array}$ & 0,4809 & \\
\hline \multirow{2}{*}{ Econômica } & Produto Interno Bruto - PIB & 0,5628 & \multirow{2}{*}{0,4549} \\
\hline & Trabalho e Renda & 0,3469 & \\
\hline \multicolumn{3}{|c|}{ IDSM de Passo Fundo } & 0,5960 \\
\hline
\end{tabular}

Fonte: Autoria própria (2017)

Legenda: Crítico $\square \quad$ Alerta $\square$ Aceitável $\square$ Ideal

O IDSM cultural e IDSM político-institucional apresentaram índice ideal de sustentabilidade com índices, respectivamente, de $(0,8195)$ e $(0,8275)$. Em nível aceitável de sustentabilidade se classificaram o IDSM social, índice de $(0,6300)$ e o IDSM ambiental, com índice de (0,5492). E as dimensões que merecem maior atenção, por se classificaram em nível alerta de sustentabilidade são, o IDSM demográfico que apresentou índice de $(0,2947)$ e o IDSM econômico com índice de (0,4549), conforme Figura 1. 
A partir da média do IDSM cultural, IDSM social, IDSM demográfico, IDSM políticoinstitucional, IDSM ambiental e IDSM econômico foi possível encontrar o IDS do município de Passo Fundo. No qual apresenta um IDSM de $(0,5960)$ evidenciando um nível aceitável de sustentabilidade, englobando as seis dimensões propostas, conforme pode ser observado no Quadro 9.

Figura 1 - Gráfico dos níveis de sustentabilidade do município de Passo Fundo-RS

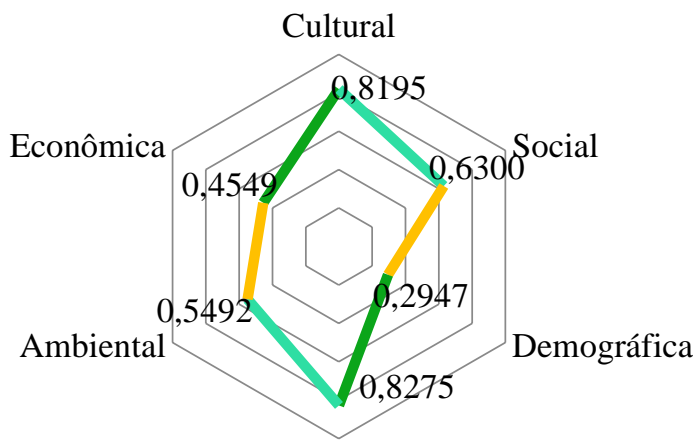

Politico Institucional

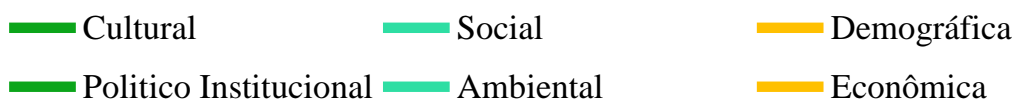

Fonte: Autoria própria (2017)

Legenda: Crítico $\square \quad$ Alerta $\square \quad$ Aceitável $\square \quad$ Ideal

Comparando com o estudo de Locatelli (2011), que analisou a sustentabilidade dos quatorze municípios do Corede Alto Jacuí (que faz divisa com o Corede Produção) através do IDSM. Os resultados mostraram que nenhum município apresentou o nível ideal de sustentabilidade, 28,57\% apresentaram nível aceitável, 71,43\% em nível alerta e nenhum município apresentou nível crítico.

No estudo de Macedo et al. (2016), os autores verificaram que nenhum dos municípios do Estado mato-grossense apresentou nível ideal de sustentabilidade, 3,55\% obteve classificação de aceitável, 96,45\% apresentou nível de alerta e, apenas, um município apresentou estado crítico.

Na pesquisa de Souza et al. (2013), identificaram o IDSM final, quando reunidas todas as capitais brasileiras, em 0,3819, nível de alerta para a sustentabilidade. Os autores afirmam, que este resultado evidencia a necessidade de um maior compromisso dos governos municipais das capitais estudadas com relação à sustentabilidade, em suas mais diversas dimensões.

Ainda que o IDSM de Passo Fundo possa ser considerado bom, em nível aceitável, ele está no limite, o que sinaliza para uma mudança de atitude, seja das instituições, como dos indivíduos de tal forma que apresente resultados satisfatórios para a construção de uma sociedade mais justa, a partir do desenvolvimento de forma equilibrada, equitativa e sustentável.

Por fim, os resultados apontados possibilitam os tomadores de decisão, tanto no setor público, como privado, uma visão conjunta dos problemas, podendo identificar suas fraquezas e suas qualidades. Assim, servir de ferramenta para direcionar as políticas públicas de forma mais eficiente em prol de um desenvolvimento sustentável ideal. 


\section{CONSIDERAÇÕES FINAIS}

Este artigo teve como objetivo identificar o nível de sustentabilidade do município de Passo Fundo-RS, em relação aos demais municípios que compõem o Corede Produção. Aplicou-se a metodologia proposta por Martins e Cândido (2008), o Índice de Desenvolvimento Sustentável para Municípios (IDSM).

A sustentabilidade é uma ferramenta-chave para o desenvolvimento econômico, preservação do meio ambiente e bem-estar da sociedade. Por isso, este artigo buscou sensibilizar os leitores, gestores públicos e privados para a importância de buscar formas de desenvolvimento sustentável de forma equilibrada e equitativa. Através da análise de indicadores que retratem a situação de determinada localidade.

O artigo não teve o intuito de investigar causas, mas identificar e analisar a situação em que se encontram as dimensões, temas e respectivos indicadores. Os resultados obtidos apontam que o município de Passo Fundo apresenta nível aceitável de sustentabilidade. Diante desse resultado, observa-se um índice de desenvolvimento sustentável que pode ser considerado bom, sobretudo, nas dimensões cultural e político-institucional.

No entanto, alguns indicadores apresentaram índice crítico como o de uso da terra, ou em alerta, como foi o caso dos indicadores de dinâmica populacional e emprego e renda, necessitando a atenção dos gestores para a criação de políticas públicas e também que revertam estes níveis e garantam maior qualidade de vida à população e, consequentemente, um melhor desenvolvimento local sustentável. Nenhuma dimensão apresentou nível crítico, porém há duas dimensões que necessitam de prioridade por se apresentarem em nível alerta, quais sejam as dimensões demográfica e econômica.

Como a definição dos índices de sustentabilidade depende dos valores dos indicadores disponibilizados por diversas fontes, deparou-se, pela falta de atualização de alguns indicadores, como também algumas páginas/portais da Internet indisponíveis, caracterizandose como uma limitação para esta pesquisa.

Para estudos futuros sugere-se aplicar IDLS (Índice de Desenvolvimento Local Sustentável), que utiliza a metodologia do IDSM, incorporando a participação de atores sociais na priorização de questões do desenvolvimento local. Ainda, a pesquisa gerou um banco de dados que proporciona identificar o IDSM para todos os municípios do Corede Produção, assim como o estudo do nível de sustentabilidade para a Região da Produção.

\section{REFERÊNCIAS}

BERTÊ, A. M. A. et al. Perfil Socioeconômico Corede Produção. Porto Alegre, 2015. Disponível em: <https://governanca.rs.gov.br/upload/arquivos/201603/17094635-perfisregionais-2015-producao.pdf >. Acesso em: 09 abr. 2019.

CMMAD. Comissão Mundial Sobre Meio Ambiente e Desenvolvimento. Nosso futuro comum. 2 ed. Rio de Janeiro: Editora da Fundação Getúlio Vargas, 1991.

FEE. Fundação de economia e estatística. Produto Interno Bruto dos municípios - 2014. Disponível em:

$<$ https://cidades.ibge.gov.br/xtras/temas.php?lang=\&codmun=431410\&idtema=162\&search $=$ rio-grande-do-sul|passo-fundo|produto-interno-bruto-dos-municipios-2014>. Acesso em: 02 nov. 2016. 
Fundação de economia e estatística. Perfil socioeconômico RS. Disponível em: < https://www.fee.rs.gov.br/perfilsocioeconomico/municipios/detalhe/?municipio=Passo+Fundo>. Acesso em: 09 abr. 2019.

FINAMORE, E. B. (Org.). Planejamento estratégico da região da produção: do diagnóstico ao mapa estratégico 2008/2028. Passo Fundo: Ed. Universidade de Passo Fundo, 2010 .

FEIL, A. A.; SCHREIBER, D. Sustentabilidade e desenvolvimento sustentável: desvendando as sobreposições e alcances de seus significados. Cadernos EBAPE.BR, v. 14, n. 3, art. 7, Rio de Janeiro, 2017.

IBGE. Instituto Brasileiro de Geografia e Estatística. Indicadores de desenvolvimento sustentável: Brasil 2015. Rio de Janeiro: IBGE, 2015. Disponível em:

$<$ https://biblioteca.ibge.gov.br/pt/biblioteca-catalogo?view=detalhes\&id=294254>. Acesso em: 11 out. 2016.

LOCATELLI, M. D. Sustentabilidade dos municípios do Corede Alto Jacuí: avaliação e diretrizes de melhoria. 2011. 213 f. Dissertação (Mestre em Engenharia) Programa de PósGraduação em Engenharia. Universidade de Passo Fundo, Passo Fundo, 2011.

MACEDO, L. O. B; CÂNDIDO, G. A.; COSTA, C. G. A.; SILVA, J. V. F. Avaliação da sustentabilidade dos municípios do estado de Mato Grosso mediante o emprego do IDSM Índice de Desenvolvimento Sustentável para Municípios. Revista Brasileira de Gestão e Desenvolvimento Regional. v. 12, n. 3, p. 323-345, 2016.

MAPAR, M. et al. Sustainability indicators for municipalities of megacities: integrating health, safety and environmental performance. Ecological Indicators, v. 83, p. 271-291, 2017.

MARTINS, M.F.; CÂNDIDO, G.A. Índice de Desenvolvimento Sustentável para Municípios (IDSM): metodologia para análise e cálculo do IDSM e classificação dos níveis de sustentabilidade - uma aplicação no Estado da Paraíba. João Pessoa: Sebrae, 2008.

MARTINS, C. H. B.; OLIVEIRA, N. Indicadores econômico-ambientais na perspectiva da sustentabilidade. Porto Alegre: FEE, 2005.

MINISTÉRIO DO MEIO AMBIENTE. Portal. Disponível em: 〈http://www.mma.gov.br>. Acesso em: 11 out. 2016.

SACHS, I. Caminhos para o desenvolvimento sustentável. Organização: Paula Yone Stroh. Rio de Janeiro: Garamond, 2009.

SEIDLER, E. P.; ANDREATTA, T.; CIECHOWICZ, I. F. S.; SPANEVELLO, R. M. A temática da sustentabilidade no meio rural a partir de uma abordagem científica. Revista Verde, Pombal - PB, v. 13, n. 5, p. 572-580, Edição Especial, 2018.

SOUZA, E. G. Índice de desenvolvimento sustentável municipal: uma análise a partir da articulação de atores sociais no município de Fagundes - PB. 2011. 157 f. Dissertação (Mestrado em Recursos Naturais) Centro de Tecnologia e Recursos Naturais. Universidade Federal de Campina Grande, Campina Grande, 2011. 
SOUZA, L. C. L. et. al. Índice de desenvolvimento sustentável para municípios (idsm): um estudo sobre o nível de sustentabilidade das capitais brasileiras. In: XV Encontro Internacional sobre Gestão Empresarial e Meio Ambiente. Anais... São Paulo: FEA/USP, 2013.

STREZOV, V.; EVANS, A.; EVANS, T. J. Assessment of the economic, social and environmental dimensions of the indicators for sustainable development. Sustainable Development, v. 25, n. 3 p. 242-253, 2017.

VEIGA, J. E. Indicadores de sustentabilidade. Estudos Avançados. v. 24. n. 68. São Paulo, 2010.

Recebido: 16/08/2020

Aceito: 27/06/2021

Publicado: Agosto de 2021

Revista Desenvolvimento Socioeconômico em debate v.7 n.1 (2021) 